El pasaje de la Crónica pasó casi intacto a un romance publicado en los Romances nuevamente sacados de Lorenzo de Sepúlveda, Amberes, 1551 (apud Durán, Romancero, BAAEE, t. 16, núm.939):

De la gran Constantinopla

su emperatriz se partía;

a Burgos había llegado,

do está el rey de Castilla...

Treinta due ñas trae consigo,

todas de negro vestian;

el Rey y otros caballeros

salieron a recebirla;

hízole toda la honra

que a su estado convenía...

Juan de la Cueva volvió a tratar el tema en un romance de su Coro febeo de romances historiales $\left(15^{88)}\right.$. Sustituye las treinta doncellas por "muchas dueñas" (Cervantes las reducirá a doce) y hace que, además de ir de luto, lleven cubierto el rostro, como en el Quijote (Durán, ibid., núm. 940):

Celebrando están las bodas del príncipe don Fernando...

sin ocuparse la corte sino en placer, y así estando, ante el Rey llena de luto una señora ha llegado, y con ella muchas dueñas cubiertas de negros paños, los rostros todos cubiertos, haciendo excesivo llanto.

La emperatriz a quien siguen, las lágrimas apartando, puesta ante el Rey de rodillas asi dice sollozando...

La visita de la Condesa Trifaldi tiene evidente parentesco con este romance de Juan de la Cueva, en el cual debió de inspirarse Cervantes para forjar uno de los episodios, aparentemente fantásticos, del Quijote; como casi todas las creaciones de Cervantes, ésta se halla hondamente enraizada en la vida de España y en los romances, que son, como el arte cervantino, una maravillosa combinación de realidad y poesía.

EMILIO GoNZÁLEZ

Hunter College, New York.

\title{
OTROS POEMAS INÉDITOS DE GUTIERRE DE CETINA ${ }^{1}$
}

Cuando José María de Cossio preparaba su hermoso libro sobre Fábulas mitológicas en España (Madrid, 1952), tuve la alegría de poderle co-

"Véase nuestra edición de "Poemas menores de Gutierre de Cetina", en EMP, 5 $(1954), 185^{-199}$. 
municar una Historia de Psique, "traducida" en octavas por Gutierre de Cetina, que permanecía inédita en el ms. 5 o6 de la Biblioteca Provincial de Toledo, cuya edición estaba preparando. Este manuscrito, estudiado ya por Henríquez Ureña y por Lucas de Torre ${ }^{2}$, guarda cierta relación con el famoso códice de Flores de varia poesia, colegido en México en ${ }_{15} 577^{3}$, puesto que también reúne abundan tes poemas de Cetina, Vadillo, Alcázar, y de otros ingenios que pasaron a Indias, como Lázaro Bejarano o Laso de la Vega. Constituye un buen corpus de poetas sevillanos de hacia 1570, aunque la mayor parte no sean otra cosa que rimadores más o menos felices. Como José María de Cossío no citó más que tres octavas de esa fábula de Psique, creo de algún interés publicarla íntegra por si algún estudioso puede aprovecharla.

En la primera y no muy feliz octava, ya advierte Cetina en qué fuente bebe. Pero Cossío anota (pp. 259-26o) que el poeta sevillano se sirve de la famosa versión de Apuleyo hecha por el arcediano Diego López de Cortegana (impresa por primera vez en Sevilla en 1513 y reeditada varias veces en el siglo xvi), cuya huella en los poetas andaluces fué muy honda. Cossío compara dos pasajes en prosa con otras tantas octavas, y el cotejo demuestra que Cetina no se remontó a grandes vuelos. "Cetina - dicese eleva pocas veces de la simple narración, y ello hace más sugestiva que su poema la versión primorosa del Arcediano sevillano. Pero fuera de esta comparación, la fábula del poeta sevillano tiene encanto, y muy principalmente en la misma sencillez y limpieza de su estilo poético".

El mismo manuscrito guarda todavía tres nuevos sonetos de Cetina, y otro con numerosas variantes que mejoran la edición de Hazañas. Aunque nada pueden añadir a los ya conocidos, me parece oportuna esta ocasión para sacarlos del olvido.

Zaragoza.

José Manuel Blegua

f. $93 \mathrm{r}^{9}$ HISTORIA DE PSIQUE, TRADUCIDA

Cuenta Apuleyo que, mientra él mudado fue en asno, los ladrones que servía una hermosa virgen han robado el día que sus bodas atendía;

5 a la cual, por hacer menos pesado su infortunio, una vieja así decía, mientra que con palabras la consuela, contándole de Psique esta novela:

Tres hijas tuvo un rey, tiernas doncellas 10 de hermosura extraña y delicada;

2 P. Henríquez Ureña, "Nuevas poesías atribuidas a Terrazas”, RFE, 5 (1918), 49 ss. (Aunque Henríquez Ureña asegura que el ms. está "escrito en excelente letra de principios del siglo xvm", lo cierto es que pertenece a la segunda mitad del xvr). L. DE TORRE, "Algunas notas para la biografía de Gutierre de Cetina", $B A E$, 1 I (1924), 388 ss.

${ }^{3}$ Hoy en la B. N. M., ms. 2373. Véanse los artículos de Renato Rosaldo, "Flores de baria poesia. Apuntes preliminares para el estudio de un cancionero manuscrito mexicano del siglo xvr", $H, 34$ (1951), 177-18o y 523-550, y "Flores de baria poesia. Un cancionero inédito mexicano de 1577", $A b s, 15$ (1951), 373-396; 16 (1952), 91-122. 
la beldad de las dos (si bien son bellas) como cosa mortal era alabada; mas la de la menor era ya entre ellas por Venus de las gentes adorada:

15 Venus la muestra al hijo, y con gran furia

f. $93 v^{0}$ le demanda venganza de esta injuria.

Ya las mayores dos, casadas siendo, cada cual con un rey vive contenta, y en el matrimonial yugo viviendo

2o parece que mayor descanso sienta; sola quedaba Psique, que plañiendo con su padre se está muy descontenta, porque por su beldad maravillosa ninguno osa pedirle por esposa.

25 El padre que buscar desea partido, al dios que está en Milesio sacrifica. -"En el yermo más solo y ascondido dejalda sola -en su respuesta explica-: llevalda como a muerta, que marido

3o mortal no debe haber - le certifica-, mas un dios volador, desnudo y ciego,

f. $94 \mathrm{r}^{8}$ que el mundo abrasa con ponzoña y fuego".

Los padres con el pueblo y con gran llanto y con fúnebre pompa, extraña, oscura

35 la llevan al lugar que el idol santo le dijo, destinado a su ventura.

Con cera y triste son, con bajo canto, con luto, cual se va a la sepoltura, juntos del monte a la más alta parte

$4^{0}$ la dejan sola y cada cual se parte.

Céfiro sopla, y como vela en nave hinche el vestido a Psique, y blandamente en alto la levanta, y con süave sueño la deja cerca de una fứente

45 y una casa real, do mientra el grave caso la admira, así decir se siente: "Psique, todo esto es tuyo, está sin pena; vente a bañar, después vendrás a cena".

Las invisibles siervas obedesce

$5^{0}$ Psique, y de los vestidos se despoja, y en el baño que allí luego aparesce, de la cabeza al pie se baña y moja. Un vaso preciosísimo se ofresce con mil varios olores en que escoja,

55 y después de lavada y de él untarse entra en un rico lecho a recrearse.

Levantada después Psique y vestida, a mesa de tres pies se pone a cena, donde (puesto que fue muy bien servida),

60 por no ver quién la sirve, lo cree apena. Amor le estaba cerca, que herida siente el alma por ella en cuita y pena; de instrumentos un son también se oía, y de voces muy dulce melodía. 
f. $95 \mathrm{r}^{9} \quad 65$ Cuando pensó dormir, tornada al lecho, en el sueño metida alto y profundo, sin armas llega Amor, de amores hecho prisión, y echó el cuerpo sin segundo; vencido, sobre aquel hermoso pecho,

70 se rinde el vencedor de todo el mundo, tomándola primero por su esposa: ioh felice, oh gentil copia amorosa!

Levantada, pues, Psique al nuevo día, después que el volador dios desparece,

75 sin ver ninguna, mil damas oía, que a su servicio cada cual se ofrece. Ella se lava y peina, y repartía el cabello en mitad, como paresce; y estando así, entre sí dice gozosa:

f. $95 \mathbf{v}^{\mathbf{0}} \quad$ Lo Las hermanas, el caso oído habiendo, al padre vuelven con angustia y lloro, y de aquel monte al fin, Amor queriendo, Céfiro las levanta y trae al coro

85 de Psique, que con gozo recibiendo las hermanas, les da muy gran tesoro. Después, por no enojar a Amor, al viento manda las vuelva al monte en un momento.

Las crueles hermanas, envidiosas

9o de tal prosperidad, sin reposarse, habiendo con maneras cautelosas pensado cómo a Psique han de mostrarse, volviendo a verla, entre mil otras cosas, le aconsejan que quiera asigurarse

95 matando al invisible y fiero esposo, el cual es un dragón muy venenoso.

f. $96 \mathrm{r}^{\mathrm{9}} \quad$ Vesla aquí con cuchillo y lumbre ardiente sobre el dormido Amor, con saña rea; mas viendo su beldad clara, eminente,

100 deja de ejecutar obra tan fea. Una flecha tocando el ardor siente, y a mirar vuelve el hijo de la dea: la lucerna lo quema, y despertando huye, y ella de un pie lo ase llorando.

105 Mas no pudiendo ya más sustenerse, en tierra con dolor cae, y se queja; de allí, cuanto el mirar puede extenderse, mira el airado Amor que se le aleja. Desesperada al fin, deja caerse

110 de un gran río, el cual salva la deja de la otra parte. Allí, mientra recela, el dios Pan con palabras la consuela. a las cuales el caso extraño cuenta;

115 finge que con injurias muy villanas Amor la echó de sí con grande afrenta. Ella[s] crédula[s] son, como inhumanas, y cada cual, de tanto bien hambrienta, 
lanzándose del monte, cuál primero,

120 con su muerte pagó el pecado fiero.

Venus, sobre delfines recreando, entre tanto se está en el oceano, cuando una palomilla, que volando del cielo baja en el salado llano,

125 dícele: "Deja, oh diosa, el ir holgando por el mar, que tu hijo está mal sano; de una gota de aceite y fuego ardiente

f. $97 \mathrm{r}^{9}$ quemado, llora del dolor que siente".

Visto Venus a Amor con villanía,

$13^{0}$ le riñe con semblante airado y fiero: "¿Tú amas -dice- a la enemiga mía, a quien debías llevar" al fin postrero?" Después con amenazas le decía: "El arco y alas y saetas quiero".

135 Vesla allá, que con Juno y Ceres anda, quejando desto, y su favor demanda.

Con sus palomas Venus sube al cielo, pide a Mercurio, a Júpiter; y a Nido le ruega que corriendo el mundo a vuelo

140 el destierro de Psique sea sabido. Él la pregona, y dice en su libelo que la hermosa Venus ha ofrescido siete besos a aquel que se la entregue y la muerte a cualquier que se la niegue. ${ }^{5}$

f. $97 \mathrm{v}^{0} \quad 145$ Psique, buscando en tanto a su marido, al templo de la diosa Ceres viene, la cual halla que había recogido todo cuanto a cocer el pan conviene. Duélese Ceres de ella y, con gemido,

$15^{\circ}$ gran[de] pasión de su destierro tiene; mas por no ir contra Venus la desecha de sí, y ni la defiende ni aprovecha.

Vase al templo de Juno, y de rodillas le cuenta la ocasión de sus antojos,

155 esmaltando con perlas las mejillas, que derramando van los bellos ojos. Juno tiene piedad de sus mancillas, mas no pone remedio a sus cordojos; antes, por no enojar a Venus bella, 160 despide de sí presto a la doncella.

f. $98 \mathrm{r}^{9} \quad$ Mas Psique, que el marido anda buscando, a la amorosa estancia al fin arriba, donde, por los cabellos arrastrando, la ponen en presencia de la diva.

165 Mira cómo la están aquí azotando Tristeza airada y la Congoja esquiva. Venus, que el corazón tiene encendido todo en furor, se rasca en el oído.

Después, varias semillas ${ }^{6}$ ayuntando,

* En el ms. llegar.

5 En el texto entrega, niega.

- Tachado legumbres. 
i 70 que aparte cada cual a Psique manda, y mientra está la mísera cenando, Amor cumple por ella esta demanda. Venus se maravilla, y va pensando que impidiendo el Amor sus obras anda.

165 Un pan le da a la fin de su fatiga, y a nuevo mal la triste Psique obliga.

f. $98 v^{9}$ "Pasa el río y verás en la sombrosa selva ovejas con lana de oro fino; de ella me trae -dice- presurosa".

180 Psique quiso ahogarse en el camino, mas una caña (de su mal piadosa) la instruye ${ }^{7}$ y dice (por querer divino) mientra el ganado duerme, que recoja la lana que en las matas se despoja.

185 Venus la envia al infierno, a Proserpina, que le traiga de afeite una bujeta. Psique, pensando que $a^{s}$ morir camina (por menos mal la muerte se haya eleta), a echarse de una torre se destina;

19o mas las piedras estorban que cometa tal error, y hablándole le muestran una ciudad, y para allá la adiestran.

f. $99 \mathrm{r}^{\mathrm{a}}$

Ya por el leñador pasa grosero, sin que a cargar le ayuda, aunque lo pida.

195 En tanto ya de Estigie al lago fiero llegó y en la gran barca es ya metida. Del pasaje a Carón paga un dinero, y otro guarda, que pague a la salida. Ves el viejo que ruega y la conjura

2oo que lo embarque, mas Psique no se cura.

Después que pasa la laguna muerta y las malvadas tres rastrilladeras, llega al honrado can, sobre la puerta, que con tres bocas guarda crudas, fieras.

205 De dos panes que trae, el uno acierta a dar al mostruo, y guarda muy de veras el otro para darle a la tornada, como fue de la torre amaestrada.

f. $99 \mathrm{v}^{9}$

Atormentado el can, tanto camina

210 por la casa infernal, toda ahumada, que hallando a la bella Proserpina, de Venus le recuenta la embajada. $\mathrm{Ni}$ a reposarse ni a sentarse inclina, ni a comer, ni a otra cosa, aunque rogada;

215 mas la bujeta espera con gran pena, que luego se la da, cerrada y llena.

Dando a Cervero Psique el pan segundo, y el dinero a Carón, ya se tornaba, mas diole un ansia, la mayor del mundo, 220 por abrir la bujeta que llevaba. Abierta, entró en un sueño muy profundo.

' En el ms. instituie.

${ }^{8}$ En el ms. al morir. 
Amor de una finiestra la miraba; con una flecha la despierta, y mueve que a Venus vaya y la bujeta lleve.

f. $100 \mathrm{r}^{0} 225$ De alli, volando al cielo, al gran Tonante ruega, porque de amor obrar se siente, que por mujer le dé a Psique, su amante. Él lo besa y abraza dulcemente; el águila de Júpiter volante

23o tiene en el pico el fuego fiero ardiente; Mercurio, en el celeste territorio, todos los dioses llama a consistorio.

Júpiter a los dioses dice y prueba que es bien que sea de Amor Psique la esposa.

235 Mercurio abaja, y presto al cielo lleva a Psique, con tal nueva muy gozosa; la cual por diosa Júpiter aprueba, hecha inmortal, y luego los desposa, haciendo que el licor de ambrosía sienta;

f. $100 v^{0}$

240 de que Venus se aplaca y se contenta. Bodas hacen espléndidas, reales, con fiesta, pompa, fasto y gran riqueza, y el dios perseguidor de los mortales hace olvidar a Psique su tristeza.

245 Las deas y los dioses inmortales admirados están de su belleza. Mientra a la mesa son, esparcen flores las Horas, con mil suertes de colores,

De allí los dos amantes deseosos

$25^{\circ}$ a restaurar se van de sus tormentos al rico lecho, adonde muy gozosos despiden los pasados pensamientos. No seáis, pues, amantes, envidiosos ni presumáis más que ellos de contentos;

255 que entre ellos dos nació la mayor parte del gozo que en el mundo se reparte.

\section{A UNA DAMA, QUEDANDO VIUDA}

f. $125 \mathrm{v}^{0}$

Como joya oriental, rica y preciosa, entre vil tierra envuelta y encerrada, descubre su valor de ella sacada y se muestra más clara y más hermosa; como parece el sol tras tenebrosa nube, que su beldad tuvo ocupada; cual va nave segura y descargada, salida de tormenta peligrosa; como queda mejor el peregrino que en bosque obscuro y con peligro ha entrado, cuando salido de él halla el camino;

como oro de metal bajo apartado, tal, señora, vuestro ánimo divino queda, de sujeción baja librado. 
Notorio es en el mundo aquel tormento que en el infierno Tántalo padece, do el agua y el manjar le desfallece, teniendo entre los dos perpetuo asiento.

5 Yo en el infierno acá que el sentimiento a un alma triste enamorada ofrece, de un fiero desear, que le parece, infernalmente atormentar me siento.

Mas jay!, ¿qué digo yo?, que desvarío;

10 de mil almas que arder en vivo fuego y el mío, injusto mal no merecido.

$Y$ de tanto es más grave el daño mío: que él desea el manjar que no ha probado, y yo el que solia gozar, y he ya perdido.

f. $129 \mathrm{r}^{0}$ SONETO

Si mientra el hombre al sol los ojos gira, ciego del resplandor busca un desvío, ¿cómo un flaco mirar ante el sol mío, cuanto se ciega más, tanto más mira?

Si una sola gloria un alma aspira, puesto que mi deseo es desvario, visto un suave mirar, honesto y pío, ¿a dónde el desear me lleva y tira?

Si de lo que ha de ser certeza tengo,

1o de mil almas que arder en vivo fuego he visto, ¿para qué busco otro indicio?

¿A qué me trae el Amor? ¿Dó voy? ¿Dó vengo, haciendo de mi vida, al vulgo juego del alma, lastimero sacrificio?

f. $318 \mathrm{r}^{0}$

SONETO

Ojos, rayos del sol, luces del cielo, que con un mirar manso y amoroso, en el trance mayor, más peligroso, soléis de mí apartar cualquier rescelo.

5 ¿Qué ceño tan cruel, qué obscuro velo es el que me mostráis tan riguroso? ¿Qué's del dulce mirar, grave y hermoso, con que el alma soléis poner consuelo?

¿Qué es esto? ¿No sois vos aquellos ojos ue me solian valer y asigurarme?

No me soléis vos dar mil desengaños?

Pues, ojos, ocasión de mis enojos, ¿por qué ahora miráis para matarme? ¿Cabe en tanta beldad tales engaños?

- Variantes que arroja la ed. de Hazañas, t. 1, p. 143: 2 con un volver; 3 más fuerte y peligroso; 4 que me solíades dar cualquier consuelo; 6 tan temeroso?; $7-8$ ¿Qué es del blando mirar, grave, amoroso / que apartaba de mí cualquier recelo?; $10 \mathrm{me}$ suelen; 11 ¿No me habéis dado vos mil... ?; 14 ¿Caben en tal beldad tales...? 